\title{
Asthma and the microbiome: defining the critical window in early life
}

\author{
Leah T. Stiemsma ${ }^{1,2}$ and Stuart E. Turvey $2,3,4^{*}$
}

\begin{abstract}
Asthma is a chronic inflammatory immune disorder of the airways affecting one in ten children in westernized countries. The geographical disparity combined with a generational rise in prevalence, emphasizes that changing environmental exposures play a significant role in the etiology of this disease. The microflora hypothesis suggests that early life exposures are disrupting the composition of the microbiota and consequently, promoting immune dysregulation in the form of hypersensitivity disorders. Animal model research supports a role of the microbiota in asthma and atopic disease development. Further, these model systems have identified an early life critical window, during which gut microbial dysbiosis is most influential in promoting hypersensitivity disorders. Until recently this critical window had not been characterized in humans, but now studies suggest that the ideal time to use microbes as preventative treatments or diagnostics for asthma in humans is within the first 100 days of life. This review outlines the major mouse-model and human studies leading to characterization of the early life critical window, emphasizing studies analyzing the intestinal and airway microbiotas in asthma and atopic disease. This research has promising future implications regarding childhood immune health, as ultimately it may be possible to therapeutically administer specific microbes in early life to prevent the development of asthma in children.
\end{abstract}

Keywords: Microbiota, Asthma, Early life, Critical window, Hygiene hypothesis, Microflora hypothesis

\section{Background}

Recent evidence supports a role of the intestinal microbiome in the development of childhood asthma and atopic disease. Animal model studies have made significant advancements in the quest to understand the gut-lung axis; identifying large-scale shifts in gut microbial compositions in asthma and allergy-induced mice and manipulating the intestinal microbiome with antibiotics, which enhanced the severity of these diseases [1-3]. However, with the advancement of DNA and RNA sequencing technologies and the establishment of large longitudinal human birth cohorts, it is becoming clearer that gut microbial dysbiosis in human atopic diseases is characterized not by global changes to the composition of the intestinal microbiota, but by taxa-specific shifts in abundance at the family, genus, and even species' levels [4-6]. Perhaps unsurprisingly, these taxa-specific changes are

\footnotetext{
${ }^{*}$ Correspondence: sturvey@cw.bc.ca

${ }^{4}$ Department of Pediatrics, BC Children's Hospital, 950 West 28th Avenue, Vancouver, BC V5Z 4H4, Canada

Full list of author information is available at the end of the article
}

most prominent within the first 100 days of life, during which the human immune system is most plastic in its development [4-6]. Given these scientific developments, this review aims to provide an overview of the recent advances in human microbiome research in asthma and atopic disease.

\section{The global burden of asthma and atopic disease}

Allergic asthma is an immunoglobulin E (IgE)-mediated chronic inflammatory disease of the airways [7]. Other manifestations of IgE-mediated or "atopic" diseases include: atopic dermatitis (also referred to as eczema), allergic rhinitis, and food allergy [8]. These diseases typically manifest in early childhood and can be chronic lifelong burdens for many people. However asthma is often viewed as the most burdensome atopic disorder, due to the prevalence (235 million people worldwide) and associated mortality (an estimated nine asthma-related deaths per day in the United States) $[9,10]$. Asthma has become the most prevalent childhood disease in recent decades, affecting approximately one in ten children 
worldwide [8]. Aside from the obvious danger associated with asthma, this disease is very disruptive to a normal daily lifestyle for children, and is the leading cause of emergency room visits and absenteeism from school [11].

Some of the most striking data related to asthma prevalence comes from the United States, where it was reported from 1999 to 2009, that the proportion of people diagnosed with asthma increased by $15 \%$ [10]. In other Westernized countries (e.g. Canada, Australia, and the UK) the prevalence of this disease was reported to be even higher (up to $30 \%$ in some countries), while many countries in Eastern Europe and Asia report a much lower prevalence of this disease $(\sim 5 \%)[8,12,13]$. This rapid increase in prevalence of asthma (and other atopic diseases) as well as the apparent geographical disparity suggests an etiology that is more complex than population genetic variation.

\section{'The post-industrial epidemic'}

The underlying cause of asthma is a complex product of genetic and environmental factors resulting in significant heterogeneity of the disease. Parental history of asthma increases the likelihood of developing this disease, however assessment of this factor alone is not enough to confirm a person's risk of asthma development [14-16]. There is also evidence of a strong link between sex and increased risk of asthma development in children, as boys are more likely to develop childhood asthma than girls $[17,18]$. Further, genome-wide-association-studies have identified candidate genes that play a role in asthma susceptibility (ORMDL3 and SMAD3) [19]. Thus it is clear that human genetics contribute to asthma pathogenesis, however the rapid rise in asthma prevalence suggests changing environmental factors are biasing the developing human immune system toward these hypersensitivity diseases [20].

In addition to the within-generation rise in the prevalence of asthma, there is also an inverse relationship between the incidence of infectious diseases and hypersensitivity diseases, where a high incidence of infectious diseases appears to protect against allergic and autoimmune diseases [21]. Further, the geographical disparity of asthma and atopic diseases is shifting, as developing countries become industrialized and their living conditions become more like the Western world [22]. Thus it appears that there may be a link between the development of hypersensitivity diseases and the urbanization or modernization of society [23]. Many urban environments have similar characteristics (lower air quality, higher population density, lower economic status) that predispose populations to asthma; and similar to the geographical disparity of this disease, rural areas with comparable environments do report greater incidences of hypersensitivity diseases [24, 25]. There is also the possibility that urbanization does not support optimal immune development due to a decrease in exposure to environmental microbes as humans shift from an outdoor lifestyle to a more indoor lifestyle that is characteristic of urban societies [26].

This concept of decreased microbial exposure in modern or more urban societies has become a booming research area in the etiology of immune dysregulation. One particular arm of asthma etiology in particular, focuses on factors associated with improved health and hygiene; for example, increased antibiotic exposure, and household size [23, 27-35]. In particular, David Strachan extensively studied the relationship between household size and atopic disease in the late 1980s, and his initial findings led him to propose the hygiene hypothesis of allergic disease in 1989 [36]. This hypothesis sets the stage for the current analyses assessing the role of microbial exposure in the development of asthma and other hypersensitivity disorders.

\section{External and internal microbes as protectors against asthma}

The hygiene hypothesis

The hygiene hypothesis proposes that a lack of early life exposure to microbes alters early life immune system priming and, consequently, increases susceptibility to atopic diseases [20]. Strachan theorized that older siblings promote increased exposure to environmental microbes through inevitable unhygienic contact, which results in decreased likelihood of atopic disease development in younger siblings [36]. He supported his hypothesis by showing that household size was inversely correlated with the development of hay fever (i.e. allergic rhinitis) in a cohort of 11,765 children [37]. Since Strachan's original proposal, the hygiene hypothesis has expanded to include additional environmental factors (such as mode of birth, antibiotic exposure, household pets, etc.), which also alter the microbial exposure of infants [33-35]. Further, with substantial improvements in genetic sequencing technology, the role of indigenous microbes has also been added to the mix.

\section{The microflora hypothesis}

The microflora hypothesis extends Strachan's hygiene hypothesis by emphasizing the role of microbes residing in and on the human body (collectively known as the human microbiota) [38]. Originally, these microbes were considered to be commensal, having little effect on human physiology [38]. However they have since been implicated extensively in human health and development, and it is clear that there is a microbial-immune cell interface, in which cross-talk between microbes and 
immune cells aids in the development of immune tolerance [39-42]. Notably, the focus of this hypothesis is the gastrointestinal tract, one of the most populated zones of the human body [38]. It proposes that perturbations to the colonization and composition of the intestinal microbiota (dysbiosis), disrupts this natural microbeimmune cell interface, biasing the developing infant immune system toward a hyper-sensitive (allergic) state $[38,43]$. In support of the microflora hypothesis, a recent study found that uncontacted Amerindians (indigenous peoples of the Americas) exhibited higher levels of bacterial and functional diversity in their skin and fecal microbiota than any other human population previously reported, suggesting that modern societal practices (perturbations) have strong implications in the development of the microbiota [44]. Regarding the role of the intestinal microbiome in asthma, the gut-lung axis attempts to explain the mechanisms guiding gut microbe-lung immune cell cross talk.

\section{The gut-lung axis}

\section{Innate immunity microbial crosstalk}

The gut-lung axis attempts to mechanistically define how microbes in the gut might influence immune function in the lung [45]. One potential connection is through interactions of the gut microbiota with pattern recognition receptors of the innate immune system [46]. It is well established that pathogen-associated molecular patterns (PAMPs) such as lipopolysaccharide (LPS), CpG, and peptidoglycan can stimulate Toll-like receptor (TLR) signaling, which confers downstream activation of many genes that regulate inflammation and innate immune responses [47]. Similar to the antigen-recognition and IgE-mediated hypersensitivity pathways, dendritic cells (DCs) are also the intermediaries of gut microbiotaimmune cell cross talk, as they regularly sample gut microbes in the intestinal lumen or lymphoid tissues [46]. DC sensing of gut microbiota PAMPs promotes immune tolerance in the intestine, but also results in phenotypic changes to DCs and migration to the mesenteric lymph node (MLN) to promote $\mathrm{T}$ cell priming [48]. In the MLN, T cells also acquire homing molecules (e.g. CCR4, CCR6), which initiate migration to other parts of the body, including the respiratory mucosa [49].

Thus it is possible that interactions with specific gut microbes, via their corresponding PAMPs, could result in varying phenotypic changes in DCs, with downstream effects on lymphocyte priming/homing and ultimately, shifts in anti-inflammatory responses in the airways [49]. In a house dust mite (HDM) model of allergic inflammation, chronic intranasal exposure to endotoxin (bacterial LPS) has been shown to protect mice from HDM-induced asthma [50]. The proposed mechanism of this protection is through A20 (ubiquitin modifying enzyme)-mediated inhibition of HDM-induced recruitment of conventional DCs to the lungs and mediastinal lymph nodes [50]. Further, prior 2-week treatment of mice with LPS suppressed proliferation and differentiation of adoptively transferred CD4+ HDM-specific 1-DER T cells in the mediastinal lymph nodes into IL-5 and IL-13-secreting T-helper (Th)-2 cells, highlighting the $\mathrm{T}$ cell priming effects of these DCs [50]. Though this is not a gut microbiota mediated pathway, it does highlight the ability of bacterial PAMPs (specifically LPS) to alter DC recruitment to the lungs and protect mice against asthma symptoms.

\section{Role of microbial-derived metabolites—short chain fatty acids}

Another area of gut-lung axis research involves microbial-derived metabolites, such as short chain fatty acids (SCFAs). SCFAs are direct by-products of bacterial fermentation of carbohydrates and are key energy sources for many host tissues and gut bacterial species [51]. There are three major SCFAs, acetate, propionate, and butyrate, which are present in a molar ratio of 60:20:20, respectively [51]. These metabolites are known to modify gene expression through inhibition of histone deacetylases (HDACs), cytokine and chemokine production, and cell differentiation, proliferation, and apoptosis [52]. With regard to immune tolerance and inflammatory mechanisms, butyrate and propionate induce extrathymic T-regulatory (T-reg) generation through direct interactions with $\mathrm{T}$ cells and indirect interactions through DCs, potentially through the inhibition of HDACs [53]. Clostridial species are prominent SCFA producers, and butyrate production by these particular bacteria was associated with the generation of peripheral T-reg cells in the colon [54]. In a HDM-mouse model of experimental asthma, both acetate and propionate were capable of reducing cellular infiltration into the airways after HDM exposure [55]. Systemic propionate treatment modified bone marrow hematopoiesis and enhanced the generation of DC and macrophage precursors and subsequent recruitment of DCs less effective in promoting Th-2 cell polarization in the lungs [55]. In a later study using the same asthma mouse model, maternal intake of acetate was shown to reduce allergic airways disease in the adult offspring of mice [56]. Notably, both these studies initially assessed the role of a high fiber diet on the production of SCFAs and colonization of intestinal bacteria-highlighting the influence of diet, mediated by gut microbial changes, on the development of the immune system $[55,56]$. The latter study, however, emphasizes intrauterine effects on the infant immune system, mediated by maternal diet, suggesting the need to consider prenatal prevention strategies using these gut microbial metabolites [56]. 


\section{Microbial influences on epigenetics}

It is also possible that the intestinal microbiota is linked to lung immunity through microbe-mediated epigenetic modification. Distinct whole blood DNA methylation patterns were associated with two major bacterial phyla, either Firmicutes or Bacteroidetes and pathway analysis revealed differential methylation (associated with a high or low Firmicute/Bacteroidetes ratio) among genes enriched in functional networks such as cardiovascular disease, inflammatory responses, obesity, and lipid metabolism [57]. Further, production of bacterial methyl groups, cofactors (e.g. folate), and enzymes (e.g. methyltransferases) can both directly and indirectly affect host DNA methylation, and consequently may bias cell differentiation toward or against an immune profile that confers tolerance $[58,59]$. There is also evidence that early life farm microbial exposures may influence the methylation of genes related to asthma and allergies [60, 61]. Lastly, reinforcing the age-sensitive role of the intestinal microbiota in hypersensitivity diseases, the presence of a conventional gut microbiota in previously germ-free (GF) neonatal (but not adult) mice decreased hypermethylation of CXCL16, which in turn decreased accumulation of invariant natural killer T (iNKT) cells (prominent in the pathogenesis of asthma) in the colon [41]. Thus ultimately, there is much more to learn regarding the mechanisms of the gut-lung axis in asthma and other lung disorders. Current research in asthma and atopic disease centers around how, mechanistically, the intestinal microbiota is linked to these disorders and whether early life changes to the intestinal microbiome can be therapeutically manipulated to promote immune tolerance.

\section{The intestinal microbiota in asthma and atopic disease}

Mechanistic studies analyzing how the intestinal microbiome is involved in asthma and atopic disease are typically conducted in mouse models of allergic inflammation. GF mice lacking a microbiota show increased allergic responses, including increased lymphocyte and eosinophil inflammation in the airways, accompanied by increased Th-2 cytokines and elevated IgE production [62]. However many animal studies also focus on roles of distinct bacterial taxa in atopic disease development. In an ovalbumin (OVA)-model of asthma, oral supplementation of mice with two types of Lactobacillus showed that protection from allergic responses is mediated by specific bacterial species [63]. Supplementation with live Lactobacillus reuteri resulted in decreased airway hyper responsiveness, while treatment with Lactobacillus salivarius had no effect on the allergic symptoms of the mice [63]. This species-specific effect was also shown using three bacterial species,
Bifidobacterium longum, Bifidobacterium breve and $L$. salivarius [1]. L. salivarius had no effect, and both Bifidobacterium species increased Peyer's patch and splenic Foxp3+ T-reg cells in infant mice [1]. However, only $B$. longum introduced in the perinatal period resulted in T-reg cell induction in adult mice and protected against allergic airway inflammation in OVA-sensitized mice [1]. Notably, the age-sensitive induction of T-regs in adult mice by $B$. longum suggests the presence of an early life window in which microbial-driven immune changes are most effective.

Antibiotics (which disturb the intestinal microbiota composition) have also been shown to increase airway inflammation in mouse models of experimental asthma $[2,64,65]$. One study showed that combined oral antibiotic treatment of mice resulted in increased allergic inflammation, characterized by increases in serum IgE and circulating basophils [65]. Conventionally raised mice showed decreased proliferation of bone-marrow resident basophil precursors compared to the antibiotic treated mice, suggesting that these shifts in immune cells were mediated by alterations to the microbiota [65]. Thus collectively, these mouse model studies show that gut microbial alterations can result in changes in lung function, but it is becoming clearer through improved mousemodels and longitudinal human cohort research, that these microbe-mediated changes in immune development are most effective in early infancy.

\section{Mouse studies suggest an early life critical window}

Age is the main driver of compositional and functional differences in the intestinal microbiota $[4,66]$. Thus it is perhaps unsurprising that many mouse studies assessing the role of the gut microbiota in atopic disease, find the results to be time sensitive (Fig. 1a). Cahenzli et al. demonstrate that global shifts in the composition of the intestinal microbiota (increased microbial diversity) in early life is required to regulate IgE production and decrease disease severity in a mouse-model of antigeninduced oral anaphylaxis [67]. In OVA- and HDM-models of allergic airway inflammation, oral infection with CagA-positive Helicobacter pylori resulted in protection against OVA and HDM-induced airway hyper responsiveness [68]. However, this bacterium-mediated protection against asthma was more apparent in mice infected neonatally compared to mice infected as adults [68]. As noted in the previous section (microbial influences on epigenetics), neonatal (but not adult-life) exposure to a conventional microbiota in GF OVA-challenged mice abrogated iNKT cells in the lungs and reduced serum IgE, proinflammatory cytokine levels, and eosinophilia in the bronchoalveolar lavage fluid, protecting mice from developing allergic asthma symptoms [41]. 


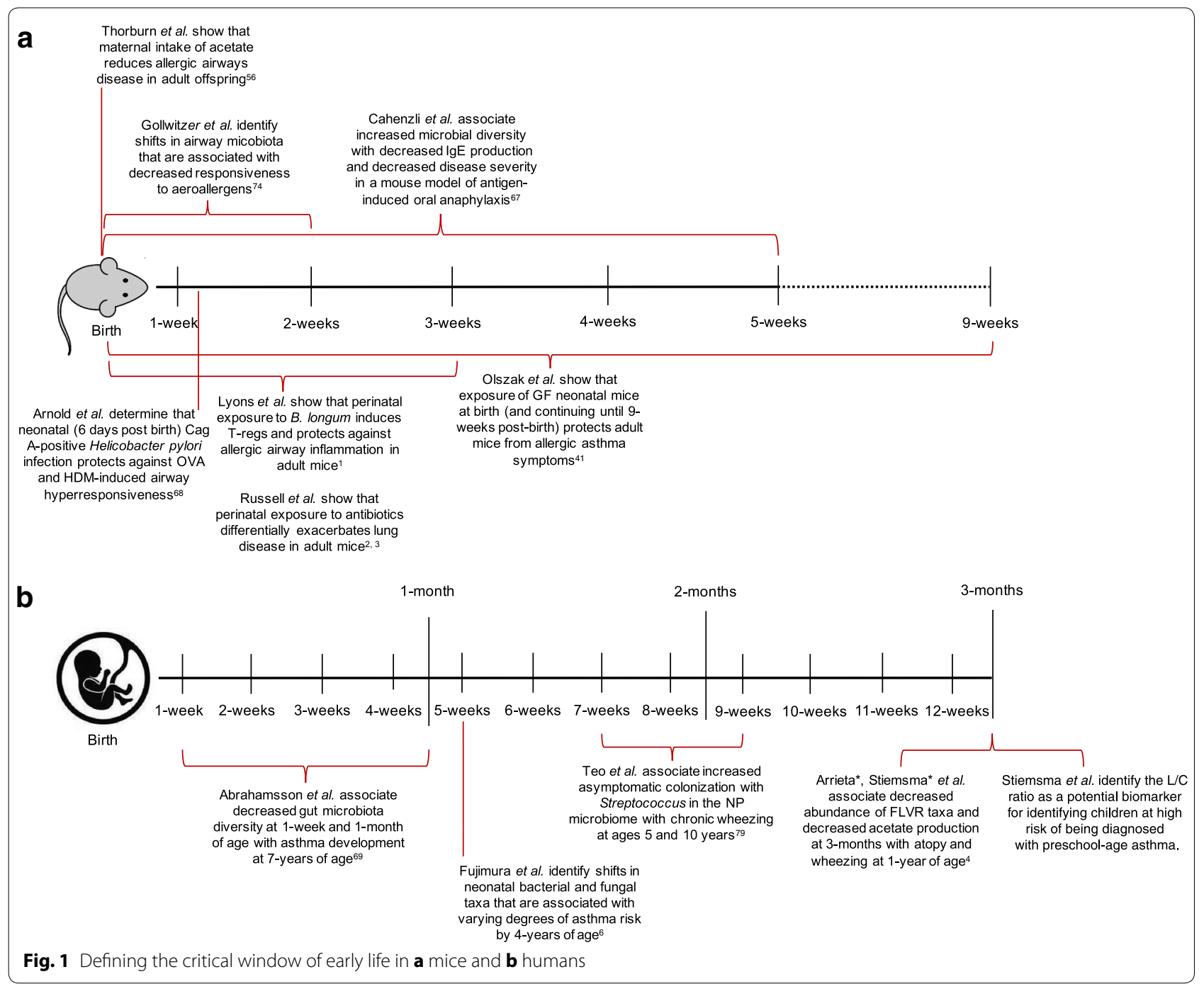

Russell et al. demonstrate the effects of early life antibiotic exposure in mice $[2,3]$. This group showed that perinatal (in utero and up to 21 days after birth until weaning) versus strictly prenatal (in utero) vancomycin treatment of OVA-challenged mice exacerbates asthmarelated immune responses [2]. Further, perinatal treatment of mice with another antibiotic, streptomycin, exaggerated lung inflammation in a Th-1/Th-17-driven model of hypersensitivity pneumonitis [3]. Notably, each antibiotic promoted expansion of specific bacterial phyla; streptomycin promoted expansion of Bacteroidetes, while vancomycin promoted expansion of Firmicutes [3]. This highlights both the selective effects of antibiotics on gut microbial taxa and the ability of an antibiotic-altered microbiota to differentially enhance disease susceptibility to specific lung diseases [3, 64]. Notably, all of these studies highlight a critical window (from birth to weaning in mice) in which microbial alterations can promote or protect against asthma and atopic diseases. However until recently, this critical window was not characterized in humans.

\section{Longitudinal human studies define the early life critical window}

Mouse studies have made substantial mechanistic strides in microbiome-atopic disease research. In parallel, improvements in DNA sequencing technology over the past decade have made analyzing the microbiomes of humans much more feasible. With these sequencing improvements, a similar 'critical window' in which microbial alterations can be associated with the development of asthma and atopic disease is also becoming more apparent in humans (Fig. 1b). Using 454-pyrosequencing, one study associated changes in gut microbial diversity at 1 -week and 1-month of age with asthma development at school age [69]. 
However more recent studies have identified shifts in specific bacterial taxa in early life, rather than global compositional changes, that are associated with increased risk of asthma later in life. In fact, our group identified decreases in the abundances of four bacterial genera, Faecalibacterium, Lachnospira, Rothia, and Veillonella (FLVR), in the 3-month fecal microbiota, which were associated with atopy and wheezing at 1-year of age among 319 infants enrolled in the Canadian Healthy Infant Longitudinal Development (CHILD) Study [4]. Atopy and wheezing are clinically used to predict asthma development in children, and subjects positive for both atopy and wheezing were most likely (compared to wheeze only, atopy only, and control subjects) to develop asthma by 3-years of age-suggesting that these early life genera shifts are associated with increased risk of asthma development [4]. Further, these four bacterial taxa ameliorated asthma in an OVA-challenged mouse model, supporting their immune-modulatory roles in protecting against asthma development [4].

Since the CHILD Study is a longitudinal cohort, our group was able to conduct a follow-up study on this same cohort when they reached 4-years of age and could be diagnosed with preschool-age asthma [5]. We found that Lachnospira remained decreased in the 3-month fecal microbiota while one particular bacterial species, Clostridium neonatale, was increased in asthmatics at this time-point [5]. Demonstrating the diagnostic potential of these particular microbes, we calculated a ratio of Lachnospira to C. neonatale (L/C) and using quartile analysis, showed that children with the lowest $\mathrm{L} / \mathrm{C}$ ratio (quartile 1) were 15 times more likely to be diagnosed with preschool-age asthma than children in the other $\mathrm{L} / \mathrm{C}$ quartiles [5]. Most interestingly, however, both of these studies identified these gut microbial changes in the first 3 months of life only, highlighting this time frame as the early life critical window during which gut microbial dysbiosis is most influential in promoting asthma and atopic disease in humans $[4,5]$.

Notably however, additional bacterial taxa as well as other microbes (e.g. fungi) have been associated with asthma and atopic disease development in children [6, 70]. In fact, a recent study published in Nature Medicine was able to distinguish asthmatic and atopic children by their neonatal (35 days post birth) intestinal microbiome compositions [6]. Children in the highest risk group showed shifts in specific bacterial and fungal taxa, highlighting roles of various gut microbes in human immune development, which are identifiable even earlier than 3 -months of age [6]. Thus, even now it is becoming more evident that; (i) there are likely many other gut microbes associated with asthma and atopic disease development in humans; and (ii) that the 'critical window' for identifying these gut microbial shifts in humans could be even smaller than 100 days post birth. Further, in an effort not to overlook a potentially obvious link between the microbiome and airway inflammation, recent studies have identified associations and mechanistic links between airway microbes and asthma and atopic disease development.

\section{Role of the airway microbiota}

Though the intestinal microbiome is one of the most populated regions of the human body, recent research supports a role of the airway microbiome in asthma and atopic disease pathogenesis. In an OVA-induced mouse model of asthma, administration of a common gut pathogen, E. coli, to the lung was shown in a TLR4-dependent manner to induce $\gamma \delta$-T cells, decrease activation of lung DCs, and abrogate Th- 2 cytokine production to confer protection of mice from allergic airway inflammation [71].

In humans, airway microbial dysbiosis has been associated with increased risk of asthma [72, 73]. 16S rRNA analysis of sputum samples showed higher bacterial diversity and increased abundance of Proteobacteria in asthmatic adults compared to non-asthmatic adults [73]. Another adult study analyzing the bronchial microbiota was able to identify differences in microbial composition associated with asthma severity [72]. When compared to healthy controls, severe asthmatics were enriched in Actinobacteria and Klebsiella species [72]. However compared to patients with moderate asthma, patients with severe asthma were enriched in many Actinobacterial taxa and showed decreased abundances of Proteobacteria [72].

Continuing the early life theme, Gollwitzer et al. provide evidence of a 2 -week window in which shifts in the airway microbiota are associated with decreased responsiveness to aeroallergens and the induction of Helios $^{-}$T-regs in a programmed death ligand 1 (PD-L1)mediated manner [74]. If PD-L1 is blocked only in the first two weeks of life and allergic airway inflammation is induced after 4-weeks of age, the exaggerated allergic airway inflammation in neonatal mice is maintained to adulthood [74]. Further, in a study of 234 human children, researchers associated early (7-9 weeks post-birth) asymptomatic colonization with Streptococcus in the nasopharyngeal (NP) microbiome with chronic wheezing at ages 5 and 10 years [75]. Interestingly, they also suggest the NP microbiome as a determinate for the spread of respiratory infections to the lower airways, which are also significant risk factors for asthma development [75]. Thus there may be specific early life non-pathogenic airway microbes associated with asthma, but it is also possible that dysbiosis in the airway microbiota is the mediator 
between respiratory infections and subsequent development of asthma.

\section{Conclusions and future directions}

In conclusion, the current literature suggests a role of the microbiome in asthma and atopic disease development, with particular emphasis on early life dysbiosis. Notably, recent studies have identified shifts in specific bacterial genera and species, which could ultimately be applied as probiotic interventions prior to the development of asthma. These probiotic interventions could be given directly to the baby in early infancy once all safety concerns have been addressed. Another option for colonizing the infant is through maternal exposure to these microbes either before or after delivery. Prior to establishing these probiotic regimens however, shifts in early life gut and airway microbes could also be applied as microbe-based diagnostics to identify children at the highest risk of developing asthma and related allergic diseases.

Before any of these preventative or diagnostic techniques can be applied, future research should focus on validating the current findings in additional longitudinal human cohorts and improving humanized microbiome mouse models of airway and lung inflammation to mechanistically characterize the microbe-immune cell interactions promoting or protecting against asthma and atopic disease. Additionally, targeted-metabolomic and shotgun metagenomic sequencing strategies using stool, urine, and potentially breast-milk samples in human cohorts will better characterize the functional roles of these specific taxa in infant immune development.

Further, to better elucidate this early life critical window in humans, additional longitudinal cohorts should begin stool sample collection beginning at birth and continuing up to age 1 year (with at least bi-weekly collection points within the first 3-montths of life). Additionally, the collection of additional biological samples (namely blood and urine) during the first 3-months of life (though this is not often feasible) would be ideal to determine whether these gut microbial alterations occur prior to immunedysregulation or vice versa.

Moreover, although this review focuses on the bacterial microbiome in asthma, there are many other microbial organisms (fungi and other eukarya, and viruses) that also play key roles in host physiology and immune development [6, 76-79]. Also, with the characterization of other microbiomes within the human body (i.e. placental, blood, breast-milk), it is likely that we will identify even more microbial taxa that are associated with airway diseases. As discussed in the previous sections, there is evidence in mice that asthma is a developmental origin disease, mediated by maternal gut microbial alterations in utero [56]. Thus it will be important to incorporate multi-biome analyses to potentially identify: (i) how children are being colonized with specific asthma related microbes; and (ii) roles of other microbial taxa in the pathogenesis of asthma and atopic disease. Ultimately however, this literature review presents research with promising future directions, offering an exciting outlook for future microbe-based preventative treatments and diagnostic strategies for asthma and atopic disease in children.

\begin{abstract}
Abbreviations
GF: germ-free; OVA: ovalbumin; HDM: house-dust mite; IgE: immunoglobulinE; LPS: lipopolysaccharide; PAMP: pathogen-associated molecular pattern; TLR: toll-like receptor; MLN: mesenteric lymph node; SCFA: short chain fatty acid; DC: dendritic cell; iNKT cell: invariant natural killer T cell; CHILD Study: Canadian Healthy Infant Longitudinal Development Study; NP: nasopharyngeal; PD-L1: programmed death ligand-1; Th: T-helper; T-reg: T-regulatory; FLVR: Faecalibacterium, Lachnospira, Veillonella, Rothia; L/C: Lachnospira/C. neonatale.
\end{abstract}

\section{Authors' contributions}

LTS wrote the manuscript. SET supervised the project and edited the manuscript. Both authors read and approved the final manuscript.

\section{Author details \\ 1 Department of Microbiology \& Immunology, University of British Colum- bia, Vancouver, BC, Canada. ${ }^{2}$ BC Children's Hospital, Vancouver, BC, Canada. ${ }^{3}$ Department of Pediatrics, University of British Columbia, Vancouver, BC, Canada. ${ }^{4}$ Department of Pediatrics, BC Children's Hospital, 950 West 28th Avenue, Vancouver, BC V5Z 4H4, Canada.}

\section{Acknowledgements}

Not applicable.

\section{Competing interests}

The authors declare that they have no competing interests.

\section{Funding}

L.T.S. was supported in part by The Four Year Fellowship (4YF) from the University of British Columbia. S.E.T. holds the Aubrey J. Tingle Professorship in Pediatric Immunology and is a clinical scholar of the Michael Smith Foundation for Health Research. This work was supported in part by funding from The Canadian Institutes of Health Research (CIHR) and the Allergy, Genes and Environment AllerGen) Network of Centres of Excellence (NCE).

Received: 27 October 2016 Accepted: 11 December 2016

Published online: 06 January 2017

\section{References}

1. Lyons A, O'Mahony D, O'Brien F, MacSharry J, Sheil B, Ceddia M, Russell WM, Forsythe P, Bienenstock J, Kiely B, et al. Bacterial strain-specific induction of Foxp3 + T regulatory cells is protective in murine allergy models. Clin Exp Allergy. 2010;40(5):811-9.

2. Russell SL, Gold MJ, Willing BP, Thorson L, McNagny KM, Finlay BB. Perinatal antibiotic treatment affects murine microbiota, immune responses and allergic asthma. Gut Microbes. 2013;4(2):158-64.

3. Russell SL, Gold MJ, Reynolds LA, Willing BP, Dimitriu P, Thorson L, Redpath SA, Perona-Wright G, Blanchet MR, Mohn WW, Finlay BB. Perinatal antibiotic-induced shifts in gut microbiota have differential effects on inflammatory lung diseases. J Allergy Clin Immunol. 2015;135(1):100-9.

4. Arrieta MC, Stiemsma LT, Dimitriu PA, Thorson L, Russell S, Yurist-Doutsch S, Kuzeljevic B, Gold MJ, Britton HM, Lefebvre DL, et al. Early infancy microbial and metabolic alterations affect risk of childhood asthma. Sci Transl Med. 2015;7(307):307ra152. 
5. Stiemsma L, Arrieta MC, Dimitriu P, Cheng J, Thorson L, Lefebvre D, Azad MB, Subbarao P, Mandhane P, Becker A, et al. Shifts in Lachnospira and Clostridium sp. in the 3-month stool microbiome are associated with preschool-age asthma. Clin Sci (Lond). 2016;130(23):2199-207.

6. Fujimura KE, Sitarik AR, Havstad S, Lin DL, Levan S, Fadrosh D, Panzer AR, LaMere B, Rackaityte E, Lukacs NW, et al. Neonatal gut microbiota associates with childhood multisensitized atopy and T cell differentiation. Nat Med. 2016;22(10):1187-91.

7. Holgate ST. Innate and adaptive immune responses in asthma. Nat Med. 2012;18(5):673-83.

8. Mallol J, Crane J, von Mutius E, Odhiambo J, Keil U, Stewart A, Group IPTS. The International study of asthma and allergies in childhood (ISAAC) phase three: a global synthesis. Allergol Immunopathol (Madr). 2013;41(2):73-85.

9. World Health Organization: Asthma [http://www.who.int/mediacentre/ factsheets/fs307/en/]. Accessed 10 Sept 2016.

10. Fact sheet: asthma's impact on the nation. In.: CDC: Centres for Disease Control and Prevention; 2015.

11. To T, Dell S, Dick P, Cicutto L. The burden of illness experienced by young children associated with asthma: a population-based cohort study. J Asthma. 2008:45(1):45-9.

12. Beasley R. ISAAC Steering Committee. Worldwide variation in prevalence of symptoms of asthma, allergic rhinoconjunctivitis, and atopic eczema: ISAAC. The international study of asthma and allergies in childhood (ISAAC) Steering committee. Lancet. 1998;351(9111):1225-32.

13. Anandan C, Nurmatov $U$, van Schayck OC, Sheikh A. Is the prevalence of asthma declining? Systematic review of epidemiological studies. Allergy. 2010;65(2):152-67.

14. Paaso EM, Jaakkola MS, Lajunen TK, Hugg TT, Jaakkola JJ. The importance of family history in asthma during the first 27 years of life. Am J Respir Crit Care Med. 2013;188(5):624-6.

15. Burke W, Fesinmeyer M, Reed K, Hampson L, Carlsten C. Family history as a predictor of asthma risk. Am J Prev Med. 2003;24(2):160-9.

16. Subbarao P, Mandhane PJ, Sears MR. Asthma: epidemiology, etiology and risk factors. Cent Med Assoc J. 2009;181(9):E181-90.

17. de Marco R, Locatelli F, Sunyer J, Burney P. Differences in incidence of reported asthma related to age in men and women. A retrospective analysis of the data of the European Respiratory Health Survey. Am J Respir Crit Care Med. 2000;162(1):68-74.

18. Sears MR. Growing up with asthma. Br Med J. 1994;309(6947):72-3.

19. Slager RE, Hawkins GA, Li X, Postma DS, Meyers DA, Bleecker ER. Genetics of asthma susceptibility and severity. Clin Chest Med. 2012;33(3):431-43.

20. Stiemsma L, Reynolds L, Turvey S, Finlay B. The hygiene hypothesis: current perspectives and future therapies. Immunotargets Ther. 2015;4:143-57.

21. Bach JF. The effect of infections on susceptibility to autoimmune and allergic diseases. N Engl J Med. 2002:347(12):911-20.

22. Graham-Rowe D. Lifestyle: when allergies go west. Nature. 2011;479(7374):S2-4.

23. Rodriguez A, Vaca M, Oviedo G, Erazo S, Chico ME, Teles C, Barreto ML, Rodrigues LC, Cooper PJ. Urbanisation is associated with prevalence of childhood asthma in diverse, small rural communities in Ecuador. Thorax. 2011;66(12):1043-50.

24. Malik HU, Kumar K, Frieri M. Minimal difference in the prevalence of asthma in the urban and rural environment. Clin Med Insights Pediatr. 2012;6:33-9.

25. Rodriguez A, Vaca MG, Chico ME, Rodrigues LC, Barreto ML, Cooper PJ. Migration and allergic diseases in a rural area of a developing country. J Allergy Clin Immunol. 2016;138(3):901-3.

26. Ruiz-Calderon JF, Cavallin H, Song SJ, Novoselac A, Pericchi LR, Hernandez JN, Rios R, Branch OH, Pereira H, Paulino LC, et al. Walls talk: microbial biogeography of homes spanning urbanization. Sci Adv. 2016;2(2):e1501061.

27. Almqvist $C$, Cnattingius $S$, Lichtenstein $P$, Lundholm C. The impact of birth mode of delivery on childhood asthma and allergic diseases - a sibling study. Clin Exp Allergy. 2012;42(9):1369-76.

28. Negele K, Heinrich J, Borte M, Berg A, Schaaf B, Lehmann I, Wichmann H, Bolte $G$. Mode of delivery and development of atopic disease during the first 2 years of life. Pediatr Allergy Immunol. 2004;15(1):48-54.

29. Hoskin-Parr L, Teyhan A, Blocker A, Henderson AJ. Antibiotic exposure in the first two years of life and development of asthma and other allergic diseases by 7.5 year: a dose-dependent relationship. Pediatr Allergy Immunol. 2013;24(8):762-71.
30. Kummeling I, Stelma FF, Dagnelie PC, Snijders BE, Penders J, Huber M, van Ree $R$, van den Brandt PA, Thijs $C$. Early life exposure to antibiotics and the subsequent development of eczema, wheeze, and allergic sensitization in the first 2 years of life: the KOALA Birth Cohort Study. Pediatrics. 2007;119(1):e225-31.

31. Devereux $G$. The increase in the prevalence of asthma and allergy: food for thought. Nat Rev Immunol. 2006;6(11):869-74.

32. Sevelsted A, Stokholm J, Bonnelykke K, Bisgaard H. Cesarean section and chronic immune disorders. Pediatrics. 2015;135(1):e92-8.

33. Azad MB, Konya T, Maughan H, Guttman DS, Field CJ, Chari RS, Sears MR, Becker AB, Scott JA, Kozyrskyj AL, et al. Gut microbiota of healthy Canadian infants: profiles by mode of delivery and infant diet at 4 months. Can Med Assoc J. 2013;185(5):385-94.

34. Azad MB, Konya T, Maughan H, Guttman DS, Field CJ, Sears MR, Becker AB, Scott JA, Kozyrskyj AL. Infant gut microbiota and the hygiene hypothesis of allergic disease: impact of household pets and siblings on microbiota composition and diversity. Allergy Asthma Clin Immunol. 2013;9(1):15.

35. Kozyrskyj AL, Ernst P, Becker AB. Increased risk of childhood asthma from antibiotic use in early life. Chest. 2007;131(6):1753-9.

36. Strachan DP. Hay fever, hygiene, and household size. Br Med J. 1989;299(6710):1259-60.

37. Strachan DP, Taylor EM, Carpenter RG. Family structure, neonatal infection, and hay fever in adolescence. Arch Dis Child. 1996;74(5):422-6.

38. Shreiner A, Huffnagle GB, Noverr MC. The "Microflora Hypothesis" of allergic disease. Adv Exp Med Biol. 2008;635:113-34.

39. Gollwitzer ES, Marsland BJ. Impact of early-life exposures on immune maturation and susceptibility to disease. Trends Immunol. 2015;36(11):684-96.

40. Pollard M, Sharon N. Responses of the Peyer's patches in germ-free mice to antigenic stimulation. Infect Immun. 1970;2(1):96-100.

41. OlszakT, An D, Zeissig S, Vera MP, Richter J, Franke A, Glickman JN, Siebert R, Baron RM, Kasper DL, et al. Microbial exposure during early life has persistent effects on natural killer T cell function. Science. 2012:336(6080):489-93.

42. Lathrop SK, Bloom SM, Rao SM, Nutsch K, Lio CW, Santacruz N, Peterson DA, StappenbeckTS, Hsieh CS. Peripheral education of the immune system by colonic commensal microbiota. Nature. 2011;478(7368):250-4.

43. O'Hara AM, Shanahan F. The gut flora as a forgotten organ. EMBO Rep. 2006;7(7):688-93.

44. Clemente JC, Pehrsson EC, Blaser MJ, Sandhu K, Gao Z, Wang B, Magris M, Hidalgo G, Contreras M, Noya-Alarcón Ó, Lander O. The microbiome of uncontacted Amerindians. Sci Adv. 2015;1(3):e1500183.

45. Marsland BJ, Trompette A, Gollwitzer ES. The gut-lung axis in respiratory disease. Ann Am Thorac Soc. 2015;12(Suppl 2):S150-6.

46. Chieppa M, Rescigno M, Huang AY, Germain RN. Dynamic imaging of dendritic cell extension into the small bowel lumen in response to epithelial cell TLR engagement. J Exp Med. 2006;203(13):2841-52.

47. Samuelson DR, Welsh DA, Shellito JE. Regulation of lung immunity and host defense by the intestinal microbiota. Front Microbiol. 2015;6:1085.

48. Ignacio A, Morales $\mathrm{Cl}$, Camara NO, Almeida RR. Innate sensing of the gut microbiota: modulation of inflammatory and autoimmune diseases. Front Immunol. 2016;7:54

49. Mikhak Z, Strassner JP, Luster AD. Lung dendritic cells imprint T cell lung homing and promote lung immunity through the chemokine receptor CCR4. J Exp Med. 2013;210(9):1855-69.

50. Schuijs MJ, Willart MA, Vergote K, Gras D, Deswarte K, Ege MJ, Madeira FB, Beyaert R, van Loo G, Bracher F, et al. Farm dust and endotoxin protect against allergy through A20 induction in lung epithelial cells. Science. 2015;349(6252):1106-10.

51. Wong JM, de Souza R, Kendall CW, Emam A, Jenkins DJ. Colonic health: fermentation and short chain fatty acids. J Clin Gastroenterol. 2006;40(3):235-43.

52. Correa-Oliveira R, Fachi JL, Vieira A, Sato FT, Vinolo MA. Regulation of immune cell function by short-chain fatty acids. Clin Transl Immunol. 2016;5(4):e73.

53. Arpaia N, Campbell C, Fan X, Dikiy S, van der Veeken J, deRoos P, Liu H, Cross JR, Pfeffer K, Coffer PJ, et al. Metabolites produced by commensal bacteria promote peripheral regulatory T-cell generation. Nature. 2013;504(7480):451-5.

54. Furusawa Y, Obata Y, Fukuda S, Endo TA, Nakato G, Takahashi D, Nakanishi Y, Uetake C, Kato K, Kato T, et al. Commensal microbe-derived butyrate induces the differentiation of colonic regulatory T cells. Nature. 2013;504(7480):446-50. 
55. Trompette A, Gollwitzer ES, Yadava K, Sichelstiel AK, Sprenger N, NgomBru C, Blanchard C, Junt T, Nicod LP, Harris NL, et al. Gut microbiota metabolism of dietary fiber influences allergic airway disease and hematopoiesis. Nat Med. 2014;20(2):159-66.

56. Thorburn AN, McKenzie Cl, Shen S, Stanley D, Macia L, Mason LJ, Roberts LK, Wong CHY, Shim R, Robert R, et al. Evidence that asthma is a developmental origin disease influenced by maternal diet and bacterial metabolites. Nat Commun. 2015; 6.

57. Kumar H, Lund R, Laiho A, Lundelin K, Ley RE, Isolauri E, Salminen S. Gut microbiota as an epigenetic regulator: pilot study based on wholegenome methylation analysis. MBio. 2014;5(6):e02113-4.

58. Gonda TA, Kim YI, Salas MC, Gamble MV, Shibata W, Muthupalani S, Sohn KJ, Abrams JA, Fox JG, Wang TC, Tycko B. Folic acid increases global DNA methylation and reduces inflammation to prevent Helicobacter-associated gastric cancer in mice. Gastroenterology. 2012;142(4):824-33.

59. Xia M, Liu J, Wu X, Liu S, Li G, Han C, Song L, Li Z, Wang Q, Wang J, et al. Histone methyltransferase Ash 1 I suppresses interleukin-6 production and inflammatory autoimmune diseases by inducing the ubiquitinediting enzyme A20. Immunity. 2013;39(3):470-81.

60. Michel S, Busato F, Genuneit J, Pekkanen J, Dalphin JC, Riedler J, Mazaleyrat N, Weber J, Karvonen AM, Hirvonen MR, et al. Farm exposure and time trends in early childhood may influence DNA methylation in genes related to asthma and allergy. Allergy. 2013;68(3):355-64.

61. Lluis A, Depner M, Gaugler B, Saas P, Casaca VI, Raedler D, Michel S, Tost J, Liu J, Genuneit J, et al. Increased regulatory T-cell numbers are associated with farm milk exposure and lower atopic sensitization and asthma in childhood. J Allergy Clin Immunol. 2014;133(2):551-9.

62. Herbst T, Sichelstiel A, Schar C, Yadava K, Burki K, Cahenzli J, McCoy K, Marsland BJ, Harris NL. Dysregulation of allergic airway inflammation in the absence of microbial colonization. Am J Respir Crit Care Med. 2011;184(2):198-205.

63. Forsythe P, Inman MD, Bienenstock J. Oral treatment with live Lactobacillus reuteri inhibits the allergic airway response in mice. Am J Respir Crit Care Med. 2007;175(6):561-9.

64. Russell SL, Gold MJ, Hartmann M, Willing BP, Thorson L, Wlodarska M, Gill N, Blanchet MR, Mohn WW, McNagny KM, et al. Early life antibiotic-driven changes in microbiota enhance susceptibility to allergic asthma. EMBO Rep. 2012;13(5):440-7.

65. Hill DA, Siracusa MC, Abt MC, Kim BS, Kobuley D, Kubo M, Kambayashi T, Larosa DF, Renner ED, Orange JS, et al. Commensal bacteria-derived signals regulate basophil hematopoiesis and allergic inflammation. Nat Med. 2012;18(4):538-46.

66. Lozupone CA, Stombaugh J, Gonzalez A, Ackermann G, Wendel D, Vazquez-Baeza Y, Jansson JK, Gordon JI, Knight R. Meta-analyses of studies of the human microbiota. Genome Res. 2013;23(10):1704-14.
67. Cahenzli J, Koller Y, Wyss M, Geuking MB, McCoy KD. Intestinal microbial diversity during early-life colonization shapes long-term IgE levels. Cell Host Microbe. 2013;14(5):559-70.

68. Arnold IC, Dehzad N, Reuter S, Martin H, Becher B, Taube C, Muller A. Helicobacter pylori infection prevents allergic asthma in mouse models through the induction of regulatory T cells. J Clin Invest. 2011;121(8):3088-93.

69. Abrahamsson TR, Jakobsson HE, Andersson AF, Bjorksten B, Engstrand $L$, Jenmalm MC. Low gut microbiota diversity in early infancy precedes asthma at school age. Clin Exp Allergy. 2014;44(6):842-50.

70. Hollander WJ, Sonnenschein-van der Voort AM, Holster IL, Jongste JC, Jaddoe VW, Hofman A, Perez-Perez Gl, Moll HA, Blaser MJ, Duijts L, Kuipers EJ. Helicobacter pylori in children with asthmatic conditions at school age, and their mothers. Aliment Pharmacol Ther. 2016;43(8):933-43.

71. Nembrini C, Sichelstiel A, Kisielow J, Kurrer M, Kopf M, Marsland BJ. Bacterial-induced protection against allergic inflammation through a multicomponent immunoregulatory mechanism. Thorax. 2011;66(9):755-63.

72. Huang YJ, Nariya S, Harris JM, Lynch SV, Choy DF, Arron JR, Boushey H. The airway microbiome in patients with severe asthma: associations with disease features and severity. J Allergy Clin Immunol. 2015;136(4):874-84

73. Marri PR, Stern DA, Wright AL, Billheimer D, Martinez FD. Asthma-associated differences in microbial composition of induced sputum. J Allergy Clin Immunol. 2013;131(2):346-52.

74. Gollwitzer ES, Saglani S, Trompette A, Yadava K, Sherburn R, McCoy KD, Nicod LP, Lloyd CM, Marsland BJ. Lung microbiota promotes tolerance to allergens in neonates via PD-L1. Nat Med. 2014;20(6):642-7.

75. Teo SM, Mok D, Pham K, Kusel M, Serralha M, Troy N, Holt BJ, Hales BJ, Walker ML, Hollams E, et al. The infant nasopharyngeal microbiome impacts severity of lower respiratory infection and risk of asthma development. Cell Host Microbe. 2015;17(5):704-15.

76. Carpagnano GE, Malerba M, Lacedonia D, Susca A, Logrieco A, Carone M, Cotugno G, Palmiotti GA, Foschino-Barbaro MP. Analysis of the fungal microbiome in exhaled breath condensate of patients with asthma. Allergy Asthma Proc. 2016;37(3):41-6.

77. Huffnagle GB, Noverr MC. The emerging world of the fungal microbiome. Trends Microbiol. 2013;21(7):334-41.

78. Virgin HW. The virome in mammalian physiology and disease. Cell. 2014;157(1):142-50.

79. Marsland BJ, Gollwitzer ES. Host-microorganism interactions in lung diseases. Nat Rev Immunol. 2014;14(12):827-35.

\section{Submit your next manuscript to BioMed Central and we will help you at every step:}

- We accept pre-submission inquiries

- Our selector tool helps you to find the most relevant journal

- We provide round the clock customer support

- Convenient online submission

- Thorough peer review

- Inclusion in PubMed and all major indexing services

- Maximum visibility for your research

Submit your manuscript at www.biomedcentral.com/submit
BioMed Central 